\title{
O trabalho em domicílio: elementos para pensar estratégias de conciliação entre trabalho e família
}

\author{
Work at home: Elements to think the conciliation strategies between work and family
}

\author{
Patricia Maccarini Moraes *
}

\begin{abstract}
Resumo:
O toyotismo, combinado com o modelo de acumulação flexível, acarretou a flexibilização das relações de trabalho, resultando na terceirização, no desemprego e na desregulamentação dos contratos e direitos trabalhistas. No setor têxtil cresce o trabalho em domicílio que indica a autoexploração do trabalhador. A casa passa a ser lugar de produção e reprodução, pois permite às mulheres exercerem uma atividade produtiva e manterem as tarefas de reprodução. Considera-se que o trabalho em domicílio seja adotado como estratégia de conciliação entre trabalho e família. Este assunto merece atenção das políticas sociais quanto aos direitos do trabalho, bem como das políticas de atenção às famílias.
\end{abstract}

Palavras-chave: Trabalho em domicílio. Família. Conciliação.

\begin{abstract}
:
The productive restructuring has made a flexibility of labor relations, generating outsourcing, unemployment, deregulation of contracts and right labor. In the textile industry, household labor grows, what represents the worker's self exploitation. The home becomes a place of production and reproduction. It allows women to exercise a productive activity, keeping the reproduction tasks. It is considering that the work at home is used as a compromise strategy between work and family. This issue deserves attention of social policies regarding labor rights and the families care policies.
\end{abstract}

Key words: Work at home. Family. Compromisse.

\section{Introdução}

Este estudo buscou problematizar o trabalho em domicílio no setor têxtil e as estratégias de conciliação desenvolvidas pelas famílias. Essa problematização inicia-se com uma breve revisão sobre as transformações que atingiram o setor no marco das alterações da pós-reestruturação produtiva e da abertura dos comércios no Brasil, após a década de 1990.

Neste processo de reestruturação, o toyotismo, combinado com o modelo de acumulação flexível, acarretou a flexibilização das relações de trabalho. As formas de produzir e as relações de produção foram, significativamente, alteradas e resultaram na

\footnotetext{
* Assistente social. Mestre em Serviço Social pela Universidade Federal de Santa Catarina. E-mail: patymacarini@hotmail.com
} 
terceirização, no desemprego, na desregulamentação dos contratos, na degradação das condições de trabalho e no desmonte dos direitos trabalhistas.

Para resistir às crises, que são cíclicas e inerentes ao sistema capitalista, o setor têxtil apelou para formas que se baseiam na autoexploração do trabalhador, como nas situações de trabalho em domicílio. Este resulta de estratégias de descentralização e terceirização da produção, que possibilitam maior exploração da classe trabalhadora, acumulação de capital e o trânsito da produção para fora do espaço fabril. Para a realização desse trânsito foi necessário (re)utilizar espaços que na fase de industrialização foram relegados ao âmbito privado; transferiu-se, então, parte da produção para outros espaços, incluindo a casa do trabalhador. Pelas características do trabalho desenvolvido, o setor tornou-se um grande empregador de mão de obra feminina.

Essa realidade foi analisada a partir das observações oriundas da prática profissional da pesquisadora, como assistente social na região do Vale do $\operatorname{Itapocu}^{1}$ (SC), e dos resultados de sua pesquisa com trabalhadores do setor têxtil realizada para a conclusão do curso de mestrado em Serviço Social ${ }^{2}$. A região, com destaque para a cidade de Jaraguá do Sul, tem grande ênfase na produção do setor têxtil e abriga desde grandes empresas que se evidenciam nacionalmente até formas precárias de produção, como o trabalho informal e em domicílio.

Nas situações de trabalho em domicílio, atenta-se para a inter-relação do trabalho com a família, já que a casa passa a ser, ao mesmo tempo, lugar de produção e reprodução. É necessário relembrar que, no Brasil, a influência da economia internacional e do capital financeiro intensificou-se durante a década de 1990 sob a lógica dos ajustes ao modelo neoliberal. Nesse período, assistiu-se à retração do Estado, conhecida como contrarreforma, acompanhando a tendência de ajustes neoliberais que preconizavam a

1 Os municípios que compõem a região do Vale do Itapocu são: Barra Velha, Corupá, Guaramirim, Jaraguá do Sul, Massaranduba, São João do Itaperiú e Schroeder.

2 Os resultados dessa pesquisa foram apresentados e analisados na dissertação A difícil conciliação entre os três mundos: família, trabalho e qualificação profissional, apresentada ao Programa de Pós-Graduação em Serviço Social da Universidade Federal de Santa Catarina. Nesta dissertação, foram estudados trabalhadores vinculados ao setor têxtil e que, concomitantemente, estivessem inseridos no curso Técnico em Vestuário - PROEJA/ CERTIFIC do Instituto Federal de Santa Catarina. Foram entrevistados trabalhadores empregados nas indústrias têxteis, nas facções de costura e trabalhadores em domicílio. Essa pesquisa teve como objetivo geral conhecer e analisar as condições de vida e trabalho das famílias inseridas no setor têxtil na cidade de Jaraguá do Sul que estão vinculadas, por meio de um de seus responsáveis, a programas de qualificação profissional (MORAES, 2015). 
contenção dos gastos sociais e a consequente redefinição do papel do Estado no âmbito da prestação dos serviços nessa esfera (SCHÜTZ, 2013). Com isso, os serviços de apoio às famílias ofertados pelo Estado implicaram maior responsabilização por parte delas na provisão do próprio bem-estar social, a fim de compensar lacunas e insuficiências. Esses serviços passaram a ser cada vez mais mercantilizados e, portanto, tendem a ser acedidos apenas pelas famílias que possuem condições financeiras para adquiri-los. Para as famílias pobres, diante da insuficiência de serviços de assistência pública, as opções situam-se nas redes de interajuda e solidariedade familiar. Nisso, as políticas setoriais sob responsabilidade do Estado tendem a focalizar o campo da pobreza e a formalizar exigências e contrapartidas para as famílias usufruírem de bens e serviços.

Além disso, a crescente participação da mulher no mercado de trabalho, cuja renda tornou-se fundamental para o sustento das famílias, não foi acompanhada de equalização nas assimetrias de gênero nem da ampliação de políticas de apoio, sejam públicas ou privadas. Todas essas questões impõem às famílias trabalhadoras um desequilíbrio entre trabalho e responsabilidades/demandas familiares. Esta tensão tem sido tradicionalmente resolvida no âmbito privado, principalmente pela sobrecarga de trabalho feminino, à medida que a mulher assume a dupla jornada de trabalho, conforme demonstrado nos estudos de Torres et al. (2004) e Gama (2014).

A discussão sobre a família é relevante, pois, conforme Saraceno (1995) e lasi (2007), a reprodução da força de trabalho no modo de produção capitalista é sustentada pelas atividades laborais realizadas pela família e na família. Desta forma, a família atua como mecanismo de produção de mais-valia por meio do trabalho doméstico não remunerado (das mulheres), que participa da produção (que integra a formação) do valor através do seu papel na reprodução da força de trabalho e como fator socializador no capitalismo (GAMA, 2012), pois "não há como existir um processo social de produção apartado da reprodução da vida social - ambos são momentos diferenciados, mas não autônomos, de uma mesma forma social." (GAMA, 2012, p. 152).

No contexto da produção capitalista, o trabalho privado de reprodução - trabalho doméstico, de cuidados e administração da casa, realizado na família, especialmente, pelas mulheres - faz-se imprescindível, tanto para a manutenção da força de trabalho como para a própria vida. Porém, apesar da importância da esfera familiar na sustentação 
do desenvolvimento capitalista e do fato de essa esfera arcar com os custos da reprodução, insiste-se na naturalização do trabalho não pago desenvolvido no âmbito da família e, consequentemente, em sua "invisibilidade".

Assim, evidenciam-se as dificuldades das famílias para equilibrar as tensões entre trabalho e demandas familiares, pois estas duas esferas, regidas por lógicas diferentes, dividem o mesmo espaço. Esse contexto articula-se com a transferência da produção para fora do espaço fabril, como no setor têxtil. Com base nisso, busca-se problematizar a situação das famílias que desenvolvem o trabalho em domicílio. Essa problematização será ilustrada pelos relatos de algumas trabalhadoras de Jaraguá do Sul e por outras pesquisas realizadas nesse mesmo setor. Para finalizar, serão apresentadas hipóteses e questões problemáticas que devem ser colocadas com maior ênfase na pauta de discussões das políticas sociais e do Serviço Social.

Inicialmente, serão apresentados aspectos gerais do setor têxtil e das transformações pelas quais ele passou para se ajustar ao contexto de crises do capital.

\section{Aa transformações no setor têxtil e as consequencias para os trabalhadores}

As transformações ocorridas no setor têxtil estão articuladas com a totalidade do universo da produção e também sofrem pressões das relações econômicas do país. Reafirmam-se as consequências que a flexibilidade introduziu na organização produtiva, entre as principais: desemprego, ressurgimento de velhas formas de trabalho precarizado e redução dos custos sociais do trabalho, uma vez que os trabalhadores exploram sua força para o capital e se permitem ser lesionados em seus direitos fundamentais. Este setor sofreu inflexões, a partir das políticas de ajuste neoliberal, com os impactos da abertura econômica dos mercados em busca de estabilização monetária e da concorrência com países altamente competitivos, como a China (BÄRH, 2012).

Um dos piores períodos de recessão da indústria brasileira de confecção ocorreu no início da década de 1990, momento da abertura comercial, iniciada no governo Collor, somado à entrada de produtos importados, o que provocou uma redução na produção nacional e até a falência de empresas. Para garantir a competitividade e manter-se no mercado, algumas empresas iniciaram, lentamente, um processo de reestruturação do setor e apostaram em inovações tecnológicas (ARAÚJO; AMORIM, 2002, p. 279). Devido a 
essa reestruturação, mantiveram-se ativas e, à custa de prejuízos ao trabalhador, têm conseguido competir internacionalmente.

Os dados da Associação Brasileira da Indústria Têxtil e de Confecção (ABIT), referentes ao ano de 2013, mostram que mais de 32 mil empresas de confecção estão instaladas no país e cerca de $80 \%$ são de pequeno e médio porte. A associação estima que cerca de 1,7 milhão de pessoas estejam empregadas de forma direta, sendo $75 \%$ no segmento de confecção. Somando-se os empregos diretos e indiretos, o número de trabalhadores ocupados nas indústrias têxteis e de confecção alcança mais de 4 milhões de pessoas. Destas, mais de 70\% são mulheres (ABIT, 2013).

O estado de Santa Catarina destaca-se, nacionalmente, nesse setor produtivo por ser o segundo maior polo têxtil e de vestuário do Brasil. Este tipo de indústria possui uma participação de $17,74 \%$ no setor industrial catarinense: a têxtil representa 6,91\% e a do vestuário 10,83\%, respectivamente. A região do Vale do Itajaí e o norte do estado, onde se localiza a região do Vale do Itapocu, destacam-se no segmento (FIESC, 2014).

As empresas têxteis situadas na região do Vale do Itapocu foram afetadas pela crise da economia e pela concorrência com os produtos importados. Uma das respostas adotadas pelas empresas foi demitir as trabalhadoras da costura. Algumas foram recontratadas anos depois, mas com salários muito menores do que recebiam na época da demissão. Outras, sem possibilidade de colocação no mercado formal, foram incentivadas a trabalhar como costureiras autônomas, na informalidade. Nesta última situação, as máquinas de costura foram acomodadas em espaços arranjados, muitas vezes, num canto da casa. Essa prática difundiu-se na região do Vale do Itapocu, num cenário de alta transformação tecnológica, de informatização dos processos produtivos, de trabalho especializado e da existência do exército industrial de reserva. Destarte, observa-se que a atividade de costura nas indústrias do setor ainda se mantém, basicamente, manual, baseada na dupla "costureira-máquina" (ARAÚJO; AMORIM, 2002; SCHÖRNER, 2000).

A informalidade do trabalho, no Brasil, que aumentou significativamente a partir da década de 1990, é compreendida como um aviltamento ao trabalho assalariado, devido aos processos de terceirização e à ausência de direitos trabalhistas. As relações de trabalho informais são reconhecidas como autônomas, independentes, com 
consentimento do Estado e, no fundo, estão diretamente subordinadas ao capital e se integram à sua organização produtiva. Neste contexto, a produção do setor informal aparece como produção e reprodução do movimento de valorização do capital (TAVARES, 2004).

No Brasil, é crescente o número de desempregados que buscam na informalidade estratégias de sobrevivência, o que faz crescer o contingente de cooperativas, empresas familiares, trabalho em domicílio e micro e pequenas empresas. No setor têxtil, como consequências do trânsito da produção para fora do espaço fabril, surgem as facções e o trabalho em domicílio, assim, não se compra, diretamente, a força de trabalho, mas o trabalho, serviço e mercadoria. O trabalho informal é, assim, uma perversa inserção do trabalhador no mercado. A partir disso, vêm à tona outras formas de trabalho e de relações produtivas: trabalho informal por peça ou por hora, trabalho em domicílio, trabalho subcontratado, entre outras. Estas "novas" formas que terceirizam a produção, os riscos e os custos apresentam um alto risco de insustentabilidade devido à instabilidade do mercado. Bärh $(2012$, p. 27) destaca aspectos fundamentais dessa terceirização:

\footnotetext{
Os serviços terceirizados quando realizados próximos aos domicílios familiares estão sujeitos a serem absorvidos pelos demais membros da família, principalmente quando se tratar de mão de obra feminina, onde em muitos casos são compartilhados os afazeres domésticos com os profissionais, envolvendo inclusive o trabalho infantil, expedientes de trabalho além dos normais permitidos pela legislação trabalhista e a informalidade.
}

A produção nessas condições é descentralizada e fragmentada. O pagamento, na maioria das vezes, é contabilizado por peça, por produção, o que exige uma dedicação muito grande dos trabalhadores para auferirem uma renda maior. É um trabalho altamente nocivo à saúde, pois exige muitas horas do dia e consiste em atividades repetitivas em locais, muitas vezes, insalubres, pois os espaços são adaptados no interior das próprias casas. Como se trata de uma atividade informal, em sua maioria sem qualquer normatização, a garantia de uma renda regular depende, unicamente, da quantidade produzida e não conta com cobertura de direitos trabalhistas e previdenciários (PEREIRA, 2013). 
Para os empresários, apresentam-se muitas vantagens nesse tipo de trabalho: economia no uso de instalações e de máquinas; redução nos custos referentes à contratação e à gestão da mão de obra; redução dos custos com aluguel e flexibilidade para enfrentar crises e flutuações nas demandas. "Além disso, existe o fato de que nas facções há a utilização da força de trabalho da família, que, geralmente, não é paga nem por ele e nem pelo empresário que contrata seus serviços" (SCHÖRNER, 2000, p. 132).

As facções de costura que, muitas vezes, se conformam em pequenos empreendimentos familiares podem ser legalizadas ou não, contar com a contratação de funcionários ou não. Não se trata de um trabalho marginal, mas que escapa à regulamentação e se subordina, diretamente, aos processos de exploração do capital. Esse serviço de facções é utilizado por $83 \%$ das empresas do segmento têxtil e de vestuário de Santa Catarina, e 63\% destas empresas revelam obter vantagens ao economizarem com salários e encargos sociais. Para as facções, a subcontratação significa 25\% a menos de faturamento (LINS, 2000 apud CALEFFI, 2008).

O processo produtivo descentralizado em diversos locais e regiões cria uma massa elevada de mais-valia e se ressalta fragmentado, pois:

Há, também, a fragmentação da fragmentação da produção, isto é, "empresários" que contratam faccionistas para a realização de serviços. Acontece, porém, que se esses não dão conta do serviço contratam outros faccionistas para realizarem parte do serviço para ele. Além disso alguns faccionistas, com mais empregados, para fugirem dos encargos sociais, dividem suas máquinas na casa dos vizinhos ou conhecidos, que acabam prestando serviços para ele, que por sua vez presta serviços para outros (SCHÖRNER, 2000, p. 134).

Carvalhal (2007), em pesquisa realizada com costureiras que trabalhavam em domicílio ou em facções em uma região do Paraná, apontou que todas as mulheres estudadas recebiam por peça produzida e que algumas delas contribuíam para a Previdência Social como autônomas. O salário por peça converte-se na forma mais fácil de descontos salariais e fraudes capitalistas em que "a exploração dos trabalhadores pelo capital se efetiva, aqui, mediante a exploração do trabalhador pelo trabalhador" (MARX, 2013, p. 624). Essa forma de organização do trabalho impulsiona uma autoexploração por parte do trabalhador (CALEFFI, 2008; MOSER, 1985). 
Uma das peculiaridades desse trabalho fora da empresa, particularmente, do realizado em domicílio, é o fato de permitir que a mulher exerça um papel nas relações capitalistas, concomitante às atividades domésticas. Conforme Harvey (2011), a mão de obra feminina passa a ser explorada sob as formas de contratos parciais e subcontratos, o que permite o desenvolvimento de sistemas de trabalho doméstico e familiar e o ressurgimento de ofícios de cunho patriarcal feitos em casa. Nesse processo de transferência de trabalho das indústrias para as facções e para os domicílios, a costura e a revisão são as principais atividades terceirizadas, atividades estas reconhecidas como femininas.

Um estudo de Moser (1985) apontou que a totalidade da mão de obra empregada na linha de montagem era composta por mulheres. Os dados da ABIT do ano de 2013 mostram que essa realidade não foi totalmente alterada. Esse predomínio das mulheres no setor têxtil pode ser justificado pela divisão sexual do trabalho que, historicamente, destinou a elas as atividades manuais para as quais se exige pouca qualificação. A incorporação das mulheres à indústria apropriou-se dos valores do patriarcado, que as submetia ao poder do homem. Sem o rompimento dessas estruturas de poder, estabelecidas socialmente, ela se sujeita ao capital por meio da venda de sua força, num regime produtivo alienante e estafante.

Na sequência, discutir-se-á a inserção no trabalho em domicílio como uma das formas adotadas pelas famílias para responder às tensões entre trabalho e demandas familiares.

\section{O trabalho em domicílio como estratégia de conciliação entre trabalho e família}

Marx (2013) retratou as condições do trabalho em domicílio no período préindustrial, que se apresentava como uma esfera de exploração de capital erigida na retaguarda da grande indústria. Naquele período, esse tipo de trabalho era utilizado para a fabricação de rendas, e os trabalhadores, ao invés de se concentrarem nas manufaturas, atuavam nas residências. $O$ trabalho era parcelado e acontecia nas casas das mestras, que eram também muito pobres, ou então era exercido por mulheres que trabalhavam em suas próprias casas, sozinhas ou com a ajuda dos filhos. A jornada, nessas condições, era extensa, geralmente, das 8 horas da manhã até às 8 horas da noite, com uma hora e meia de intervalo para refeições, feitas de maneira irregular e, na maioria das vezes, nos próprios locais de trabalho. Conforme demonstrou Marx, esses locais eram fétidos e 
insalubres. Percebe-se, então, que, desde a manufatura, o trabalho em domicílio é superexplorado pelo capital e realizado em condições precárias e insalubres. Essas condições não são totalmente diferentes no período atual de terceirização da produção.

A Organização Internacional do Trabalho $(\mathrm{OIT})^{3}$ define trabalho em domicílio "como a produção de bens ou serviços feita por um indivíduo, no seu domicílio ou em lugar de sua escolha, em troca de salário, sob a especificação de um empregador ou intermediário" (LAVINAS et al., 2000, p. 4). Estas autoras destacam que essa definição enfatiza a subordinação do contratado para com o contratante e não, propriamente, o local da atividade.

Para Tavares (2004, p. 171):

\begin{abstract}
A transferência de parte da produção realizada fora das fábricas, mediante trabalho domiciliar, além de se constituir numa invasão ao ambiente familiar do trabalhador, propicia a prática de trabalho não pago, que incorpora toda a família, não deixando lugar para outras dimensões humanas na vida do trabalhador.
\end{abstract}

No entanto, os trabalhadores apontam algumas "vantagens" do trabalho em domicílio: não há deslocamento, o que significa economia de tempo e de custos com transporte; as mulheres, principalmente, apontam o fato de conseguirem ficar junto dos filhos e da família, pois a casa é, ao mesmo tempo, espaço de produção e residência; e o salário que é pago por peça ou produção pode ser maior que o obtido diretamente na fábrica - mas este só será alcançado por meio da autoexploração (SCHÖRNER, 2000). Para as mulheres, impõe-se um delicado equilíbrio entre a necessidade de realizar um trabalho gerador de renda e a manutenção de seu papel tradicional de mãe e esposa; representa trabalho em tempo parcial, que resulta em complementação do orçamento familiar e em uma superposição do espaço e do tempo profissional e doméstico, o que favorece o acúmulo de tarefas. Esse quadro reforça a divisão sexual do trabalho, demarcando claramente qual a posição a ser ocupada pela mulher. Reforça também a transformação da família em pequenas unidades de produção e reprodução social nas quais se articulam atividades econômicas, domésticas e escolares, sem limites claros entre o que pertence ao trabalho e o que pertence à vida familiar (SCHÖRNER, 2000).

\footnotetext{
${ }^{3}$ Definição contida na Convenção da OIT assinada em 1996.
} 
Com base nesses apontamentos, percebe-se que, no trabalho em domicílio, a casa passa a ser, ao mesmo tempo, o lugar da produção e da reprodução. Há uma sobreposição de funções, principalmente, da mulher, no trabalho produtivo e reprodutivo. A prática do trabalho no domicílio impõe condições degradantes aos trabalhadores e representa uma invasão ao ambiente familiar, pois homens, mulheres e crianças dele participam, submetendo suas forças à extração da mais-valia.

As observações da realidade do trabalho fabril no setor têxtil indicam que impera a rigidez de horários de início e fim da jornada de trabalho, que é, muitas vezes, prolongada pela exigência de horas-extras e de demandas das demais dimensões da vida do trabalhador, que são desconsideradas. Somam-se a isso as dificuldades de conciliar os horários de trabalho com os horários dos serviços aos quais a família precisa ter acesso para dar conta da provisão, do bem-estar aos seus membros, tais como creches, escolas, serviços de saúde, entre outros. Isso é problemático, pois dificulta a conciliação entre trabalho e demandas familiares para os trabalhadores.

Na região do Vale do Itapocu, realidade de onde partem as observações, as creches ampliaram o horário de atendimento - que se inicia por volta das 4 horas ou 5 horas da manhã. Apesar disso, a família precisa fazer diversas articulações e rearranjos na rotina para dar conta do deslocamento até a creche e, depois, até o trabalho, por exemplo. Outro fator que dificulta o equilíbrio entre trabalho e demandas familiares é o fato, em regra geral, das creches e escolas não admitirem crianças doentes. Nessas situações, a família, principalmente, a mãe, é chamada a responder pelo cuidado.

De maneira geral, os trabalhadores são colocados na difícil condição de equilibrar duas esferas distintas da vida - trabalho e família - mas que se implicam mutuamente e são fundamentais para a organização da vida social e da reprodução. O dilema vivido para a articulação entre trabalho e família se apresenta como um grande desafio ao universo familiar no século XXI (MOSER, 2014). Afinal, o papel de reprodução desempenhado pela família é o eixo de sustentação da força de trabalho que garante a sobrevivência dos indivíduos (IASI, 2007). As questões relativas a essa conciliação ou articulação, historicamente, foram resolvidas no âmbito privado pelas mulheres, uma vez que "o modelo tradicional de conciliação entre trabalho e família estava assentado em rígidos 
papéis de gênero, no modelo de família biparental e em uma organização do trabalho e da produção que não corresponde mais à realidade" (OIT, 2010, p. 2).

O desafio de equilibrar família e trabalho surge em decorrência das transformações sociofamiliares, principalmente com a incorporação da mulher no mercado de trabalho, e do aumento da participação de pais e mães em atividades laborais, sem que se alterassem as expectativas colocadas socialmente em relação às funções da família. Gama (2012) destaca que ainda predominam as concepções culturais que consideram a reprodução uma responsabilidade das mulheres e não como uma necessidade da sociedade.

Espera-se que a família resolva, de forma privada, as tensões com o trabalho, articulando seus recursos internos e/ou por meio de serviços adquiridos no mercado. Vale ressaltar que essas tensões ainda não adquiriram densidade nas respostas via políticas públicas no Brasil, pois são pífias as medidas de apoio ofertadas às famílias (MORAES, 2015).

O estudo sobre essa temática surgiu na Europa na década de 1960 e é apoiado pela Organização Internacional do Trabalho - OIT, que reforça:

[...] As mudanças nos papéis de gênero e na organização produtiva fizeram o modelo tradicional de conciliação (homem provedor e mulher cuidadora) entre trabalho e família entrar em crise, tornando tensa a relação entre as esferas produtiva e reprodutiva, o que é agravado pela ausência de políticas de conciliação que levem em conta as demandas sociais atuais. A dificuldade de conciliar trabalho e família gera uma série de tensões e custos tanto no local de trabalho, como nos lares e na sociedade como um todo (OIT, 2010, p. 3).

No ano de 1981, a OIT expediu duas normativas acerca do tema: a Convenção 156 e a Recomendação 165. A primeira refere-se à igualdade de oportunidades e ao tratamento para trabalhadores e trabalhadoras com responsabilidades familiares e prevê medidas para evitar que sejam discriminados. Estabelece, também, que os serviços devem incoporar as necessidades desse grupo (OIT, 2010). Já a Recomendação 165 informa algumas medidas de acesso, permanência e reintegração dos trabalhadores com responsabilidades familiares, por meio de mecanismos que favorecem melhorias nas condições de vida e de trabalho.

Destaca-se que o Brasil não ratificou essas orientações da OIT nem outras relacionadas com a temática. A não ratificação dessas normativas pode estar relacionada 
ao momento histórico de retração dos direitos trabalhistas e sociais vivido entre os anos 1990 e 2000, período que concentrou várias medidas de desregulamentação de direitos do trabalho. As medidas da OIT opõem-se à desregulamentação da legislação social e do trabalho e restringem novas modalidades de contratação e regimes. Deriva, daí, uma possível explicação para a não ratificação das medidas pelo Brasil. Por outro lado, apresenta-se fraca a pressão dos movimentos feminista e sindical (GAMA, 2014; MOSER, 2014).

As dificuldades para equilibrar as tensões entre trabalho e família geram estresse e adoecimento. Constata-se ainda que cada vez mais o Estado reforça as funções das famílias na provisão do cuidado, ao se fazer ausente na oferta e condições de acesso a serviços públicos de apoio, ao não promover políticas de conciliação e ao corroborar a deterioração dos direitos do trabalho. Por isso, o trabalho em domicílio passa a ser uma estratégia de conciliação para muitas famílias. Esses aspectos, evidenciados por alguns estudos - Carvalhal (2007), Coimbra (2013) e Moraes (2015) - serão aqui retomados.

Trabalhar em casa torna-se uma alternativa para as mulheres na conciliação das tarefas de trabalhadora, dona de casa e mãe, além de possibilitá-las auferir uma renda que sustenta sozinha a casa ou que complementa a do marido. Esta "conciliação" entre trabalho produtivo e trabalho doméstico é apontada por Carvalhal (2007, p. 133):

\footnotetext{
Muitas vezes as mulheres "optam" por determinada função tendo em vista a possibilidade de conciliar o trabalho assalariado e as funções domésticas, inclusive o cuidado com os filhos. Isso porque ainda é a mulher que executa essas tarefas domésticas, assim como o gerenciamento delas, quando ela dispõe de outra pessoa para realizá-la, como pudemos perceber em recente pesquisa.
}

Coimbra (2013) aponta, em pesquisa realizada com costureiras que trabalham em casa para indústrias têxteis-vestuaristas de Jaraguá do Sul, que o trabalho em domicílio é o ideal para elas, pois seriam donas do próprio horário de trabalho e teriam mais tempo para cuidar dos filhos e do marido. A autora destaca que as empresas têm restrições para contratar trabalhadoras com filhos pequenos, por considerarem que estas poderiam se ausentar para cuidar da prole. Quando essas trabalhadoras são contratadas, dificilmente passam do período de experiência. O cenário agrava-se diante da insuficiência de vagas em creches, percebida não só na região do Vale do Itapocu, mas em âmbito nacional. 
Verifica-se, ainda, ausência de serviços no contraturno escolar para as crianças e adolescentes em idade de escolarização básica. Em um dos turnos, as crianças vão para a escola; nos demais, é responsabilidade da família prover cuidado e proteção.

A fala de uma das mulheres entrevistadas por Coimbra (2013) é elucidativa da "liberdade" do trabalho em domicílio:

\begin{abstract}
As vantagens que têm [de trabalhar em casa] é assim, ó: a hora que eu quiser ir pro centro eu vou, se eu preciso correr com uma criança no médico eu vou, se eu preciso ir até ali no colégio, eu já tô lá. E as desvantagens é o seguinte, se eu tiver dentro de uma empresa, registrada se você falta - você pede pro encarregado - posso leva meu filho no médico? Já não dá certo. Você faltou um dia, perdeu aquele dia, entendeu? Ou até perdeu o domingo. O meu filho tem 11 anos, se eu deixar e trabalhar numa empresa em tempo integral, a parte da tarde ele vai ficar em casa sozinho, não dá. Então eu prefiro ficar com uma facção aberta, tá de olho nele pra depois não sofrer mais tarde. Tem as vantagens de você tá registrada com décimo e férias, tudo ali, né? ... Ter os seus dias pra descansar ... mas também tem as desvantagens né? Todos os médicos que eu vou é pelo SUS, é tudo público [...]. Com 17 anos, as empresas pegam pra trabalhar, mas como a minha mais velha já tem uma bebê, as empresas não pegam tão fácil [...]. (COIMBRA, 2013, p. 211).
\end{abstract}

Elas reconhecem as consequências da ausência de direitos trabalhistas, mas, diante da necessidade de cuidar dos filhos, o trabalho em domicílio se apresenta como boa opção (COIMBRA, 2013; MORAES, 2015). Os relatos apresentados e as observações oriundas da prática profissional apontam que os componentes das famílias, sobretudo os responsáveis pelo grupo familiar, têm dificuldades para realizar as artiulações quando estão submetidos a horários rígidos de trabalho, no caso do trabalho nas fábricas.

Contraditoriamente, as mulheres demonstram o caráter ininterrupto da atividade que realizam. Uma costureira relatou:

"Pra te dizer bem a verdade, o trabalho doméstico fica, não se faz trabalho doméstico, não dá tempo. Ou tu trabalha, faz uma coisa bem feita, ou faz trabalho doméstico, tem que escolher, não dá pra fazer os dois (Costureira, 54)" (COIMBRA; ORCHARD, 2014, p. 10).

Percebe-se que, nesse tipo de trabalho, o tempo de cuidado e dedicação às atividades domésticas é escasso, uma vez que as costureiras são constantemente pressionadas pelos fornecedores das mercadorias. Sempre há prazo para atender e, caso não seja atendido, corre-se o risco de ter o fornecimento cancelado. Desta forma, parece 
que a mulher trabalhadora nunca está fora de expediente. O trabalho em domicílio permite a superposição, num só lugar, do trabalho produtivo e do reprodutivo; o espaço e o tempo se fundem no trabalho, o que conforma uma extrema exploração e precarização.

Os dados obtidos em pesquisa recente com trabalhadores do setor têxtil, em Jaraguá do Sul, revelaram que as mulheres estão inseridas em maior número no trabalho informal (MORAES, 2015). Assim como mostraram Carvalhal (2007) e Coimbra (2013), notou-se que o trabalho em domicílio está fortemente vinculado à família. Constatou-se a ausência de serviços públicos de apoio (nenhuma das famílias entrevistadas tinha acesso aos serviços e benefícios da política de assistência social) e não se percebeu medidas, por parte das empresas do setor, para amenizar o conflito dos trabalhadores para conciliar as exigências do emprego com as demandas/necessidades familiares (MORAES, 2015). Esse contexto, associado às condições atuais de trabalho nas empresas têxteis, obriga as famílias a aderir à produção em domicílio para que consigam obter remuneração e, ao mesmo tempo, desempenhar as necessidades de cunho domético/ familiar.

Conforme Saraceno e Naldini (2003, p. 277), o trabalho familiar compreende:

\begin{abstract}
Desde o trabalho doméstico em sentido estrito, ao trabalho de cuidados a familiares não autossuficientes por razões de idade ou invalidez, ao trabalho de consumo, que não compreende apenas a compra e eventual transformação de bens, mas também o trabalho necessário para utilizar adequadamente os serviços públicos e privados que hoje constituem parte importante dos recursos familiares, até o chamado trabalho de relação. Este último refere-se à actividade de criação e manutenção das relações, de comunicação dentro da família, entre esta e a rede parental, bem como entre a família ou cada um de seus membros e o sistema de serviços.
\end{abstract}

O trabalho em domicílio põe em evidência situações de exploração por impossibilitar o acesso aos direitos trabalhistas e à representação de classe, por acentuar o caráter individualista da atividade e por ser permeado pela desproteção social e pelo baixo valor pago por peça. Essa realidade atesta que, para esses trabalhadores, a ampliação dos rendimentos se dá pela via da autoexploração, ou seja, essas pessoas só conseguirão ganhar mais se aumentarem a jornada e a intensidade de seu trabalho (MOSER, 1985, SCHÖRNER, 2000, CALEFI, 2008, MORAES, 2015).

As falas das mulheres materializam a hipótese de que trabalho em domícilio funciona como estratégia de conciliação entre trabalho e família: 
Desde que eu engravidei, eu nunca trabalhei fora, então eu tive que deixar eles de lado [quando foi trabalhar em uma empresa têxtil]. Porque eu não posso faltar no serviço para levar ao pediatra, eu não posso faltar. Criança precisa porque tem pediatra, tem médico, tem negócio de creche e eu acabava jogando tudo isso pro Jacinto e era bem na parte da manhã. Ela fez cirurgia, ele tinha que levar ela. Ele gravava no celular a consulta com o médico porque chegava em casa e ele não sabia me dizer. Então ele gravava as consultas pra eu estar por dentro, saber o que médico tinha falado. A empresa não liberava. Ela fez cirurgia. Nem com atestado. O meu filho pegou pneumonia e ficou internado, eu ganhei a conta por causa disso [...]. Trabalhar fora com criança pequena é bem complicado, ainda mais estudando (Açucena) (MORAES, 2015, p. 133, grifo do autor).

Então eu tô querendo comprar uma máquina para costurar em casa, por causa da minha menina. Assim eu não tenho quem cuide dela de tarde ou pra mim deixar. A mulher que eu deixava não vai poder cuidar mais, não vai mais trabalhar com criança, então me deixou na mão, de um jeito que eu não vou conseguir. Então pra mim trabalhar, só em casa. Eu não tenho o que fazer. Trabalhar registrado não compensa. Ela vivia sempre doente. A gente estava toda vida mais no hospital do que em casa. Então trabalhar fora pra mim não compensa, pelo menos até ela ter uns 5 ou 6 anos que possa se virar. Ela ainda vai fazer 4, então depende tudo de mim. É complicado, olha, eu tô lutando para não desistir do colégio (Íris). (MORAES, 2015, p. 133-134).

Percebeu-se também que não existe separação entre trabalho familiar e remunerado quando a produção está no domicílio, pois ambos são realizados ao mesmo tempo. Por exemplo, um familiar prepara o almoço enquanto o outro costura e, quando há uma folga na costura, aproveita-se para estender a roupa, lavar a louça, brincar e dar banho nas crianças (MORAES, 2015).

A necessidade de cuidar dos filhos está entre as principais justificativas para o trabalho em domicílio. Assim, os trabalhadores vão ajustando os horários de trabalho com a rotina de cuidado (MORAES, 2015). Apesar de alguns reconhecerem o caráter exploratório da atividade que desenvolvem, seus relatos enfatizam que, diante das precárias condições de trabalho e de vida (em alguns casos), a única alternativa viável é levar o trabalho para dentro de casa.

\section{Considerações finais}

No contexto apresentado, a existência de um exército industrial de reserva, ou seja, "uma população trabalhadora adicional relativamente excedente, isto é, excessiva para as necessidades médias de valorização do capital e, portanto, supérflua" (MARX, 2013, p. 
705), confere maior liberdade às empresas para demitir e contratar trabalhadores. 0 excedente de mão de obra disponível no mercado possibilita a imposição de regras mais rígidas aos trabalhadores. Estes se veem pressionados para atender às demandas da empresa e isso inclui: não faltar, pois o setor atua com estoque limitado de peças; prazos exíguos para conclusão de lotes; e produção parcelada, na qual cada trabalhador é responsável por uma etapa. Nesse cenário, a ausência ao trabalho é extremamente problemática. Por isso, para garantir seus empregos, os trabalhadores evitam ao máximo as faltas, mesmo quando estão doentes ou quando seus filhos adoecem. Ainda que o abono às faltas decorrentes de atestado médico esteja previsto em lei, trata-se de um direito que, muitas vezes, não é reconhecido na prática pelas empresas.

Por outro lado, são constantes as pressões para que a família atue como mecanismo de proteção social. A partir de uma proposição familista ${ }^{4}$, as políticas públicas estão organizadas de maneira compensatória e temporária, associadas a uma ideia de falência da família (MIOTO, 2010). No âmbito dos serviços públicos (saúde, educação, assistência social, entre outros), é recorrente a ênfase nas soluções privadas em que a família é chamada prover as próprias necessidades. As observações oriundas da prática profissional permitem citar alguns exemplos: diante da inexistência de serviços no contraturno escolar ou com horário flexível e estendido, o pai e a mãe trabalham em turnos diferentes para que sempre tenha um adulto em casa para cuidar das crianças, idosos e dependentes; os avós (já aposentados), os irmãos mais velhos ou mesmo algum vizinho, geralmente, são responsáveis pelas crianças durante o horário de trabalho dos pais.

No trabalho em domicílio, coloca-se como problemática a junção do trabalho com a casa e com a família. Como resposta a essa problemática, os trabalhadores decidem trabalhar em casa, em condições precárias e com baixa remuneração, para que possam, concomitantemente, cuidar da casa e dos filhos. É atribuída ao trabalho em domicílio uma flexibilidade (de horários, de remuneração) que não é encontrada quando se trabalha em empresas, com horários rígidos de entrada e saída. As ausências de direitos do trabalho e dos benefícios advindos da contribuição para a Previdência Social podem

\footnotetext{
${ }^{4}$ Uma conceituação clara e precisa da proposição familista de políticas sociais pode ser encontrada em Mioto (2010).
} 
diminuir a capacidade protetiva da família e fazer com que ela recorra, novamente, às soluções privadas.

A autoexploração do trabalhador - para obter uma renda que possibilite satisfazer, pelo menos, parte de suas necessidades, os trabalhadores têm de produzir por longas jornadas e num ritmo acelerado - e o trabalho não pago que é realizado pelos integrantes da família também são questões problemáticas. $\quad 0$ trabalho domiciliar invade 0 ambiente familiar e submete os trabalhadores a altos níveis de exploração. $O$ trânsito da produção para fora do espaço fabril acaba sendo uma estratégia, escamoteada pela aparente solução que oferece ao conflito vivido pela maioria pelas famílias da classe trabalhadora, da conciliação entre o trabalho da produção e as responsabilidades familiares.

Esse conflito merece atenção diferenciada das políticas sociais, pois família e trabalho são fundamentais para a organização da vida social e interconectam-se. Trata-se de um cenário em que as famílias, geralmente, se encontram sobrecarregadas, por terem de aliar aspectos inerentes ao trabalho e às demandas familiares no mesmo espaço, o que exige adequações e submete os membros das famílias, principalmente as mulheres, a uma situação de exaustão. Com base nas experiências profissionais na região do Vale do Itapocu e nas pesquisas informadas anteriormente, constata-se que nem sempre os serviços públicos articulam-se para atender às necessidades das famílias e, constantemente, exigem e pressionam para que estas respondam pela própria proteção social. Portanto, a questão da conciliação entre trabalho e família ainda não ganhou ênfase no planejamento dos serviços de assistência social.

Assim, conforme afirmou Mioto (2010), é necessário considerar alguns indicadores das mudanças que ocorreram na sociedade: econômicas, no mundo do trabalho, de caráter tecnológico e as novas configurações demográficas que incluem famílias menores, com mais idosos, entre outras. "Tais indicadores sinalizam que a família não tem condições objetivas de arcar com as exigências que estão sendo colocadas sobre ela na sociedade contemporânea [...]." (MIOTO, 2010, p. 169).

Diante disso, sugere-se que haja organização dos serviços públicos a partir das demandas das famílias, nos seus diversos aspectos, para aliviar essas tensões. Considerase que as estratégias adotadas pelas famílias para sanar, individualmente, as questões da 
conciliação são problemáticas, pois, como apontado, submetem os sujeitos a condições cada vez mais degradantes de trabalho e de vida.

Por outro lado, faz-se necessário atentar para a persistente exploração que se apresenta no trabalho em domicílio, materializada pela desproteção social, individualização, ausência de representação de classe, subcontratação, baixa remuneração, entre outros aspectos (MORAES, 2015). A melhoria das condições de trabalho é fundamental para aliviar a sobrecarga da família. Para isso, o trabalho em domicílio precisa sair dos cantos das casas e se tornar um problema público, objeto de negociação dos sindicatos e, principalmente, uma preocupação política do Estado. A perversa estratégia de conciliação, que é o trabalho em domicílio, não pode mais ser encarada como aceitável para equilibrar as tensões entre trabalho e demandas familiares, pois esta sobrecarrega e responsabiliza as famílias.

\section{Referências}

ABIT - ASSOCIAÇÃO BRASILEIRA DA INDÚSTRIA TÊXTIL E DE CONFECÇÃO. Indústria têxtil e de confecção brasileira: cenários, desafios, perspectivas e demandas. Brasília, jun. 2013. Disponível em: <http://www.abit.org.br/conteudo/links/publicacoes/cartilha_rtcc.pdf>. Acesso em: 3 jan. 2015.

ARAÚJO, A. M. C.; AMORIM, E. R. A. Redes de subcontratação e trabalho a domicílio na indústria de confecção. Cadernos Pagu, Campinas, n. 17, p. 267-310, 2002.

BÄHR, O. G. Os dilemas da subcontratação: os limites da "redução de custos" das grandes empresas do complexo têxtil-vestuário de Blumenau. 2012. 116 f. Dissertação (Mestrado em Desenvolvimento Regional) - Centro de Ciências Humanas e da Comunicação, Universidade Regional de Blumenau, Blumenau, 2012.

CALEFFI, V. M. Reestruturação produtiva na indústria do vestuário e as implicações para a qualificação dos trabalhadores. 2008. 149 f. Dissertação (Mestrado em Educação) Centro de Ciências da Educação, Universidade Federal de Santa Catarina, Florianópolis, 2008.

CARVALHAL, T. B. O trabalho domiciliar feminino como estratégia de sobrevivência e/ou imposição do capital? Pegada, Presidente Prudente, v. 8, n. 2, p. 131-148, dez. 2007. Disponível em: <http://www4.fct.unesp.br/ceget/PEGADA82/9Texto-Terezinha.pdf.>. Acesso em: 2 nov. 2013.

COIMBRA, M. G. L. B. A cultura do trabalho em Jaraguá do Sul: um estudo sobre as trabalhadoras da indústria têxtil-vestuarista. 2013. 252 f. Dissertação (Mestrado em Sociologia Política) - Universidade Federal de Santa Catarina, Florianópolis, 2013. 
COIMBRA, M. G. L. B.; ORCHARD, M. S. E. As trabalhadoras da indústria têxtil-vestuarista de Jaraguá do Sul: conflitos étnicos e precarização do trabalho. In: SIMPÓSIO DE GÊNERO E POLÍTICAS PÚBLICAS, 3., 2014, Londrina. Anais... Londrina: Universidade Estadual de Londrina, 2014.

FIESC - FEDERAÇÃO DAS INDÚSTRIAS DE SANTA CATARINA. Têxtil e vestuário.

Florianópolis, 2014. Disponível em:

<http://www2.fiescnet.com.br/web/pt/site_topo/pei/info/textil-e-vestuario>. Acesso em: 3 jan. 2015.

GAMA, A. S. Trabalho e responsabilidades familiares no Brasil: reflexões sobre direitos do trabalho. Em Pauta, Rio de Janeiro, v. 10, n. 30, p. 149-168, 2012.

GAMA, A. S. Trabalho, família e gênero: impactos dos direitos do trabalho e da educação infantil. São Paulo: Cortez, 2014.

HARVEY, D. Condição pós-moderna: uma pesquisa sobre as origens da mudança cultural. Tradução de Adail Ubirajara Sobral e Maria Stela Gonçalves. 21. ed. São Paulo: Loyola, 2011.

IASI, M. Trabalho doméstico e valor. In: Ensaios sobre consciência e emancipação.

São Paulo: Expressão Popular, 2007. p. 123-141.

LAVINAS, L. et al. (Org.). Trabalho a domicílio: novas formas de contratualidade. Rio de Janeiro: Ipea, 2000. (Texto para discussão, n. 77).

MARX, K. O capital: crítica da economia política: livro I: o processo de produção do capital. Tradução de Rubens Enderle. São Paulo: Boitempo, 2013.

MIOTO, R. C. T. Família, trabalho com famílias e serviço social. Serviço Social em Revista, Londrina, v. 12, n. 2, p. 163-17. 2010.

MORAES, P. M. A difícil conciliação entre os três mundos: família, trabalho e qualificação profissional. 2015. 166 f. Dissertação (Mestrado em Serviço Social) -Universidade Federal de Santa Catarina, Florianópolis, 2015.

MOSER, A. A nova submissão: mulheres da zona rural no processo de trabalho industrial. Porto Alegre: EDIPAZ, 1985. (Coleção debate e crítica).

MOSER, L. Os desafios na articulação entre trabalho e família: demandas às políticas públicas e ao serviço social. In: ENCONTRO NACIONAL DE PESQUISADORES EM SERVIÇO SOCIAL, 14., 2014, Natal. Anais... Natal: Enpess, 2014.

OIT - ORGANIZAÇÃO INTERNACIONAL DO TRABALHO. Trabalho e responsabilidades familiares: novos enfoques. Brasília, 2010. (Notas da OIT, trabalho e família, 1).

PEREIRA, C. A. O trabalho domiciliar e sua importância no circuito de valorização do capital no setor de confecções. Disponível em:

<http://www.uel.br/grupopesquisa/gepal/segundosimposio/cibeliaaparecidapereira.pdf> . Acesso em: 2 nov. 2013. 
SARACENO, C. A dependência construída e a interdependência negada. Estruturas de gênero da cidadania. In: BONACCHI, G.; GROPPI, A. O dilema da cidadania: direitos e deveres das mulheres. São Paulo: UNESP, 1995. p. 205-234.

SARACENO, C.; NALDINI, M. Sociologia da família. 2. ed. Lisboa: Estampa, 2003.

SCHÖRNER, A. O arco-íris encoberto: Jaraguá do Sul, o trabalho e a história: operários, colonos-operários e faccionistas. Joinville: Oficina Comunicações, 2000.

SCHÜTZ, F. O debate sobre serviços na política social: implicações para o serviço social. 2013. 136 f. Dissertação (Mestrado em Serviço Social) - Universidade Federal de Santa Catarina, Florianópolis, 2013.

TAVARES, M. A. Os fios (in)visíveis da produção capitalista: informalidade e precarização do trabalho. São Paulo: Cortez, 2004.

TORRES, A. C. et al. Homens e mulheres entre familia e trabalho. Lisboa: DEEP. CID, 2004. (Estudos, 1). 